\title{
NIH sacrifices commercial rights in WiCell deal
}

Last month, the US National Institutes of Health (NIH; Bethesda, MD) and the WiCell Research Institute (Madison, WI) signed a memorandum of understanding that provides the government agency with access to five established embryonic stem (ES) cell lines for a nominal processing fee. Although the agreement provides NIH essentially free access to WiCell's ES cell lines, including a royalty-free sublicense to the relevant intellectual property rights (potentially saving US taxpayers millions of dollars), it also specifically restricts both diagnostic and therapeutic uses of ES cells, which may tie the hands of NIH scientists interested in developing cell-based therapies and diagnostics.

The WiCell Research Institute is a nonprofit institution established in October 1999 by the Wisconsin Alumni Research Foundation (WARF) - the nonprofit patent and licensing arm of the University of Wisconsin-Madison (UW; Madison, WI) - to advance research involving stem cells. The institute was founded to exploit the pioneering work of UW scientist James Thompson, who headed one of the first two teams to extract ES cells from human embryos (Science 282, 1145-1147, 1998).

Using funding from the Geron Corporation (Menlo Park), Thompson developed five ES cell lines that were assigned to WARF. Although three of these five cell lines are licensed to Geron, all five are licensed to the WiCell (these are covered in US Patent 5,843,780, US Patent $6,200,806$, and other pending patents), which is currently the world's largest commercial supplier of human ES cells, selling two vials of stem cells and instructions on how to grow them for $\sim \$ 5,000$.

In the September memorandum, US government researchers are granted access to all five ES cell lines, which can proliferate in tissue culture for more than a year while maintaining their potential to differentiate into derivatives of endodermal, mesodermal, and ectodermal tissue. The agreement strictly forbids the use of the original Wisconsin cell lines in any research activities designed to create embryos or develop cell-based therapies or diagnostics. If these terms are violated, researchers forfeit the right to work on the cells and the lines must be returned to the WiCell.

According to George Daley, assistant professor of medicine at the Harvard Medical School (Cambridge, MA), "What this basically is saying is that WiCell is

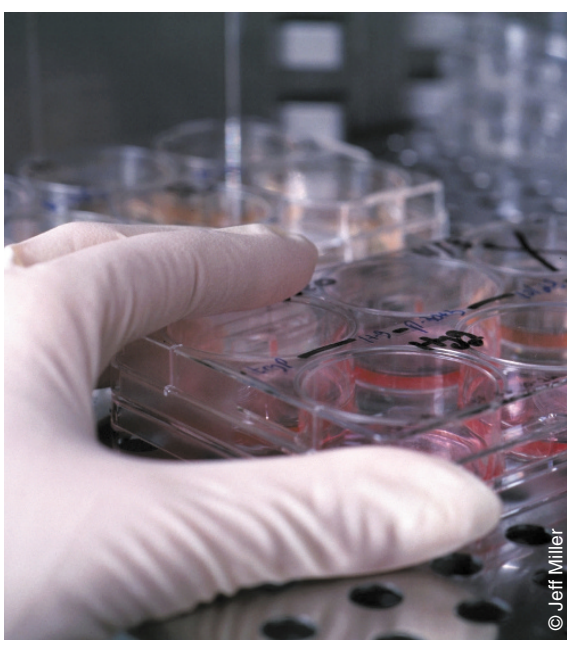

The WiCell is now the world's largest supplier of human ES cells

going to disallow any federally funded researchers from developing a cell therapy." A spokesman for the WARF stresses, however, that the ES cell lines are not designed for therapeutic use and are years away from application in cell-based therapies (e.g., for Alzheimer's and Parkinson's disease).

However, the NIH still retains patent and publication rights to any new discoveries arising from its research programs. Private companies such as Geron, which retains commercial rights to three of the five Wisconsin ES cell lines, can enter into financial discussions with NIH researchers interested in commercializing their new inventions. Without any first right of refusal to new breakthroughs by the NIH, WiCell must stand in line with companies to negotiate rights to any potentially lucrative products and licensing fees that arise from research.

WiCell will still generate profits by controlling any intellectual property rights to the original ES cells that may be needed to commercialize novel NIH discoveries. Commercialization of some of the $\mathrm{NIH}$ findings may require a license to rights to the ES-cell patents held by WiCell. Thirdparty commercialization may require separate agreement for patent rights, which under this collaboration must contain financial terms "not less favorable" than other licenses offered by WiCell-making third-party commercialization a promising source of licensing revenue for the Wisconsin institute.

Debra Robertson, San Diego, CA 